\title{
Appointment of a new Co-Editor-in-Chief, Prof. Georg Fantner, Microsystem Technologies
}

\author{
Bharat Bhushan ${ }^{1}$
}

Published online: 16 January 2022

(C) The Author(s), under exclusive licence to Springer-Verlag GmbH Germany, part of Springer Nature 2021

Microsystem Technologies (MST) - Micro- and Nanosystems, and Information Storage and Processing Systems-is a premier archival journal with high impact factor. It provides rapid publication of important and timely results on electromechanical, materials science, design, and manufacturing issues of these systems and their components. The micro- and nanosystems include MEMS/ NEMS (Micro/NanoElectroMechanical Systems), e.g., sensors and actuators, micromechatronics, optoelectronics, microfluidics and systems integration. Information storage systems include magnetic recording, optical recording, and other recording devices, Processing systems include copiers, printers, scanners and digital cameras.
It is my distinct pleasure to announce the appointment of Dr Georg Fantner, as Co-EIC, who is the head of the laboratory for Bio and Nano Instrumentation at the École Polytechnique Fédéral de Lausanne (EPFL), Switzerland. He received his Ph.D. in physics from the University of California Santa Barbara, USA. He holds a professorship in the field of Bioengineering and Microengineering at EPFL, Switzerland.

Publisher's Note Springer Nature remains neutral with regard to jurisdictional claims in published maps and institutional affiliations.

Bharat Bhushan

bhushan100@outlook.com

1 The Ohio State University, San Jose, CA, USA 